\title{
THE STUDY OF THE GAS EXCHANGE FUNCTION OF LUNGS VIA THE MATHEMATICAL MODEL OF THE FUNCTIONAL RESPIRATORY SYSTEM
}

\author{
Tetiana Semchyk, Iryna Korniush, Vira Hovorukha, Oleksandr Tashyrev
}

\begin{abstract}
Respiratory system diseases are among the most dangerous for human life. Pathologies of the respiratory system appear due to environmental pollution, the spread of epidemics, etc.. To predict the course of pathological processes, the body's response to various influences of external extreme conditions, there is a strong need to develop the imitational mathematical models, which can provide the opportunity for the fast selection of the necessary optimal breathing mode. The goal of the work was to develop the imitational mathematical model to prognose and regulate the state of the respiratory system of the organism under the indignation of the environment. To study the mechanisms of self-regulation and adaptation of the body to disturbances of the external or internal environment, a mathematical model of the functional respiratory and circulatory system was developed. The dynamics of the partial pressures and stresses of the respiratory gases in the structures of the body was described by a system of ordinary differential equations. The principles of material balance and continuity of the flow were used to construct them. The structure of the model considered several reservoirs of the alveolar space, each of which was connected to the environment by a separate section of the airways and was washed by the corresponding volume of blood in the pulmonary capillaries. On the basis of the mathematical model of the functional respiratory system, an imitational mathematical model of the gas exchange process in the lungs has been developed and investigated. The model took into account the role of the elasticity and the resistance of the lung structures in the formation of the nature of the gas exchange process under various modes of external respiration. The results of the research will allow to accelerate the selection of the optimal breathing mode to achieve a stable balance of the internal and the external environment of the body.
\end{abstract}

Keywords: imitational mathematical modeling, the elasticity and the resistance of the lung structures, the gas exchange

\section{INTRODUCTION}

The transport of gases by the respiratory and circulatory systems of the body is one of the main processes associated with the life of the human body. Significant and/or long-term deviations from normal values of oxygen concentration in the blood can cause strong pathological changes. Under the conditions of the change of external environment and internal state of the body, the action of its regulatory systems is aimed to maintain the homeostasis. An artificial lung ventilation in medicine is the bright example of the application of the models for the transport of respiratory gases in a changing environment. Ventilation of the lungs can be impaired due to the pathological changes in the respiratory apparatus such as decrease in respiratory excursions of the lungs, decrease in lung compliance, constriction of the airways causing the increase in their aerodynamic resistance, etc. [1 - 4]. Artificial ventilation of the lungs is widely used in medicine to maintain the necessary vital processes. Together with the experimental substantiation the strong theoretical background is required to carry out the successful artificial ventilation of lungs. For such purposes, simulation methods are used. The existing now research models of the gas exchange process in the human lungs [5 - 8] describe adequately enough the processes under normal conditions of pulmonary respiration and human life. To expand the area of application of mathematical models, it is necessary to take into account not only the normal conditions, but analyze the abnormal conditions that can occur both in life and in experimental conditions. The paper proposes one of the options to take into account the elasticity and the resistance of pulmonary structures simulating the process of gas exchange in human lungs using a model of the functional respiratory system [9-14].

Thus, the goal of the work was to develop the imitational mathematical model to prognose and regulate the state of the respiratory system of the organism under the indignation of the environment.

\section{MATERIALS AND METHODS}

The process of the gas exchange in the lung structures served the object of the research. On the basis of the mathematical model of the functional respiratory system, an imitational mathematical model of the gas exchange process in the lungs has 
been developed and investigated. It took into account the role of elasticity and resistance of the lung structures in the formation of the nature of the gas exchange process under various modes of external respiration. In the process of solving the formulated problems, the following methods were used: methods of mathematical modeling of functional systems of the body, methods for solving systems of differential equations, methods for solving problems of the theory of optimal control, methods of mathematical programming.

Developing the model, we used the Portnyagin optimality principle [15].Conflict situations are taken into account and modeled, arising both due to the contradictory interests of organ tissues providing them with oxygen in conditions of its deficiency, and the multi directionality of stimulating factors of regulation during the hypoxia.

\section{RESULTS AND DISCUSSION}

Mathematical model of the functional respiratory system

We have developed the mathematical model of the functional system of respiration of human organism. In this model, the respiratory process is described as the controlled dynamic system that provides the opportunity to predict the processes of the gas exchange in the organism.

The following fragments of the model relate to the process that performs the main function of the respiratory and circulatory system, namely, the timely and effective delivery of oxygen to metabolizing tissues and the removal of carbon dioxide formed during tissue metabolism. In this model, in the respiratory cycle, oxygen is transported through the airways into the alveolar space of the lungs. It enters the blood of the pulmonary capillaries through the alveolarcapillary membranes. Branching into a system of tissue capillaries, the circulatory system carries oxygen to the organs and tissues of the body via the arterial blood. The transfer of oxygen from the blood to the tissue reservoir is carried out, where tissue respiration occurs. Carbon dioxide is a product of the respiration in tissues. It diffuses into the blood and is excreted into the lungs, where it is flushed out of the body during exhalation [5]. The partial pressure of respiratory gases (oxygen, carbon dioxide and nitrogen) in the respiratory tract and alveolar space, as well as tension in the blood and fluid of tissue capillaries are considered to be the phase variables. They help to assess the state of the functional respiratory and circulatory system [7].

Depending on the goals of mathematical modeling, the apparatus of the theory of differential equations with lumped or distributed parameters is usually used to assess the functional state of the system. Since the mathematical model of the functional system of respiration and blood circulation was built to study the mechanisms of self-regulation and adaptation of the body to the disturbance of the external and/or internal environment, the dynamics of partial pressures and tensions of respiratory gases in the structures of the body is described by a system of ordinary differential equations.

To construct them, the principles of material balance and continuity of the flow were used. As an example of the structure of the mathematical model of the considered system, we present the fragments related to the subsystem of external respiration, transport and mass transfer of gases in the subsystems "blood of tissue capillary - tissue (tissue respiration)".

We consider $P_{j D}, P_{j A}$ as the partial pressure of gases in the airways $D$ and in the alveolar space $A$, respectively: oxygen $(j=1)$, carbon dioxide $(j=2)$ and nitrogen $(j=3)$. We denote $P_{j C L}, P_{j a}, P_{j c t}, P_{j \bar{v}}, P_{j t}$ as the tension of respiratory gases in the blood of pulmonary capillaries, arterial blood, blood of tissue capillaries, mixed venous blood and tissue fluid, respectively. We denote $P_{1}, P_{2}, P_{3}$ as the partial pressures of oxygen, carbon and nitrogen in the respiratory mixture, assuming that

$$
B=P_{1}+P_{2}+P_{3},
$$

where $B$ - the value of atmospheric pressure.

Then the equation describing the dynamics of $P_{j D}$ in the airways can be represented as:

$$
\frac{d P_{j D}}{d \tau}=\frac{\dot{V}}{V_{D}}\left[\tilde{P}_{j D}-\tilde{P}_{j A}\right], j=1,2,3,
$$

where $V_{D}$ - the airway volume, $\dot{V}-$ the ventilation. 
and

$$
\dot{V}=\left\{\begin{array}{l}
\frac{D \cdot \tau}{T_{a}} \sin \frac{\tau-\tau_{0}}{T_{a}} n_{i}, \text { on the breathing act (on inhalation and exhalation), } \\
0, \text { on a respiratory break, }
\end{array}\right.
$$

$$
\begin{gathered}
\tilde{P}_{j D}=\left\{\begin{array}{l}
P_{j}, \text { at } \dot{V}>0, \\
P_{j D}, \text { at } \dot{V} \leq 0,
\end{array}\right. \\
P_{j A}=\left\{\begin{array}{l}
P_{j D}, \text { at } \dot{V}>0, \\
P_{j A}, \text { at } \dot{V} \leq 0,
\end{array}\right.
\end{gathered}
$$

where $T_{a}$ - the duration of the respiratory act, $\tau_{0}$ the time of its start, and $D$ - the respiratory volume. Using the principles of material balance and

$$
\frac{d P_{j A}}{d \tau}=\frac{1}{n_{j}\left(V_{L}-V_{D}\right)}\left[n_{j} \tilde{P}_{j A} \tilde{V}-G_{j A}-n_{j} P_{j A} \frac{d V_{L}}{d \tau}\right],
$$

where $G_{j A}$ - the gas flow through the alveolarcapillary membrane, $V_{L}$ - the volume of the lungs,

$n_{j}-$ the conversion coefficients. For $G_{j A}$ the algebraic analogue of Fick's law was used:

$$
G_{j A}=k_{j} n_{j} S\left(P_{j A}-P_{j C L}\right),
$$

where $k, n$ - the coefficients of permeability of gases through the membrane, $S$ - the surface area of the mass transfer.

Deriving the equations for the transport of respiratory gases by blood, it is necessary to take into account the features of mass transfer of gases convectively. It means that oxygen is transferred in the dissolved form in blood plasma as well as chemically bound to hemoglobin $(H b)$, carbon dioxide is chemically bound to $H b$ and buffer compounds of blood $(B H)$, nitrogen is only dissolved in blood plasma.

Here we present the equations characterizing the changes in the tension of respiratory gases in the blood of tissue capillaries and in the tissue fluid of an organ:

$$
\begin{gathered}
\frac{d P_{1 c t i}}{d \tau}=\frac{1}{V_{c t i}\left(\alpha_{1}+\gamma H b \frac{\partial \eta_{c t i}}{\partial P_{1 c t i}}\right)}\left(\alpha_{1} Q_{t_{i}}\left(P_{1 a}-P_{1 c t_{i}}\right)+\gamma H b Q_{t_{i}}\left(\eta_{a}-\eta_{c t_{i}}\right)-G_{1 t_{i}}\right), \\
\frac{d P_{2 c t i}}{d \tau}=\frac{1}{V_{c t_{i}}\left(\alpha_{2}+\gamma_{B H} B H \frac{\partial z_{c t_{i}}}{\partial P_{2 c t_{i}}}\right)}\left(\alpha_{2} Q_{t_{i}}\left(P_{2 a}-P_{2 c t_{i}}\right)-G_{2 t_{i}}+\right. \\
\left.+Q_{t_{i}} B H \gamma_{B H} H b Q_{t_{i}} z_{a}-\left(1-\eta_{c t_{i}}\right) \gamma_{H b} H b V_{c t_{i}} \frac{\partial \eta_{c t_{i}}}{\partial \tau}\right), \\
\frac{d P_{3 c t_{i}}}{d \tau}=\frac{1}{\alpha_{3} V_{c t_{i}}}\left(\alpha_{3} P_{3 a} Q_{t_{i}}-\alpha_{3} P_{3 c t_{i}} Q_{t_{i}}-G_{3 t_{i}}\right),
\end{gathered}
$$


where

$$
\begin{gathered}
\frac{d P_{1 t_{i}}}{d \tau}=\frac{1}{V_{t_{i}}\left(\alpha_{t_{i}}+\gamma_{M b} M b \frac{\partial \eta_{t_{i} M b}}{\partial P_{1 t_{i}}}\right)}\left(G_{1 t_{i}}-q_{1 t_{i}}\right), \\
\frac{d P_{2 t_{i}}}{d \tau}=\frac{G_{2 t_{i}}+q_{2 t_{i}}}{\alpha_{2 t_{i}} V_{2 t_{i}}}, \\
\frac{d P_{3 t_{i}}}{d \tau}=\frac{G_{3 t_{i}}}{\alpha_{3 t_{i}} V_{t_{i}}},
\end{gathered}
$$

$\alpha_{1}, \alpha_{2}, \alpha_{3}, \alpha_{1 t_{i}}, \alpha_{2 t_{i}}, \alpha_{3 t_{i}}-$ the coefficients of solubility of the respiratory gases in blood and tissue fluid, $Q_{t_{i}}-$ volumetric blood flow rate in the capillary bed of the tissue reservoir $t_{i} ; V_{c t_{i}}, V_{t_{i}}$ - the volume of blood and tissue fluid, respectively.
The tissue blood partially released oxygen and received carbon dioxide. It is collected in the venous bed and returns to the lungs as a result of the forced circulation. During the next respiratory cycle it is enriched with oxygen, and carbon dioxide is washed out:

$$
\begin{gathered}
\frac{d P_{1 \bar{v}}}{d \tau}=\frac{1}{V_{\bar{v}}\left(\alpha_{1}+\gamma_{H b} H b \frac{\partial \eta_{\bar{v}}}{\partial P_{1 \bar{v}}}\right)}\left(\alpha_{1}\left(\sum_{t_{i}} Q_{t_{i}} P_{1 c t_{i}}-Q P_{1 \bar{v}}\right)-\gamma H b Q \eta_{\bar{v}}\right), \\
\frac{d P_{2 \bar{v}}}{d \tau}=\frac{1}{V_{\bar{v}}\left(\alpha_{2}+\gamma_{B H} B H \frac{\partial z_{\bar{v}}}{\partial P_{2 \bar{v}}}\right)}\left(\alpha_{2}\left(\sum_{t_{i}} Q_{t_{i}}-Q P_{2 \bar{v}}\right)+\left(\sum_{t_{i}} \gamma_{B H} B H_{c t_{i}} Q_{t_{i}} z_{2 c t_{j}}-\gamma_{B H} B H Q z_{2 \bar{v}}\right)+\right. \\
+\left(\sum_{t_{i}}\left(1-\eta_{c t_{i}}\right) \gamma_{H b} H b Q z_{\bar{v}}-\left(1-\eta_{\bar{v}}\right) \gamma_{H b} H b Q z_{\bar{v}}\right)+\sum_{t_{i}} \gamma_{H b} H b_{c t_{i}} V_{c t_{i}} \frac{\partial \eta_{c t_{i}}}{\partial \tau}, \\
\frac{d P_{3 \bar{v}}}{d \tau}=\frac{1}{\alpha_{3} V_{\bar{v}}}\left(\sum_{t_{i}} \alpha_{3} Q_{t_{i}} P_{3 c t_{i}}-\alpha_{3} Q P_{3 \bar{v}}\right) .
\end{gathered}
$$

Thus, the system (1) - (20) at given $\dot{V}, Q, Q_{t_{i}}, i=1, m, D, q_{t_{i}}$ and $T_{a}$ describes the change in the partial pressures and tensions of respiratory gases in the blood and fluids of tissue reservoirs and organs during the respiratory cycle. 
Mathematical model of the process of gas exchange in lungs, taking into account the elasticity of lung tissues and the resistance of the lung structures

The structure of the developed model considers the several reservoirs of the alveolar space, each of which is connected to the environment by a separate section of the airways and is washed by the corresponding volume of blood in the pulmonary capillaries. The lung elasticity $l$ and bronchial resistance $R$ were not explicitly specified in model (1) - (20). The previously described model was built under the assumption that its parameters correspond to normally functioning lungs under natural conditions of human life. Here, we consider the alveolar space connected to the environment by the airways and suppose that the elasticity of the lung tissue and the resistance of the lung structures can change depending on the conditions of the functioning and the physiological state of the lungs.

The dynamics of the partial pressures of oxygen, carbon dioxide and nitrogen in the alveolar space is described by equations (6) - (7). Further, we will assume that the elasticity $l$ changes depending on the volume $V_{L}$ and the specified elasticity $l_{0}$ of the tissues of the alveolar space of the volume $V_{L}^{0}$. The influence $l$ on the model (1) - (20) was simulated by the relations

$$
\begin{aligned}
& \frac{d V_{L}}{d \tau}=l V_{L}, \\
& l=L\left(l_{0}, V_{L}^{0}, V_{L}\right)
\end{aligned}
$$

where $L-$ known function of $l$ change.

For example, you can accept $l=l_{0} \frac{V_{L}^{0}}{V_{L}}$.

Thus, model (1) - (20), as well as relations (21), (22) simulate the process of gas exchange in the alveolar space, taking into account the effect of the elasticity parameter of lung tissues on gas exchange.

The gas exchange in the airways with the volume $V_{D}$ can be described by equations (1), (2).

Based on our ideas, the resistance $R$ of the considered airways in (1), (2) influences through $V_{D}$ and $V_{L}$. We consider $V_{D}, V_{L}$ at each respiratory cycle to change according to the ratios

$$
\begin{aligned}
V_{D}(\tau) & =\left\{\begin{array}{l}
f_{1}\left(D_{v d}\left(T_{0}\right), T_{0}, t_{v d}, \tau\right), \text { on inhalation, } \\
f_{2}\left(D_{v d x}\left(T_{0}\right), T_{0}, t_{v d x} \tau\right), \text { on exhalation, } \\
0, \text { on a respiratory break, }
\end{array}\right. \\
V_{L}(\tau) & =\left\{\begin{array}{l}
f_{1}\left(D_{v d}\left(T_{0}\right), T_{0}, t_{v d}, \tau\right), \text { on inhalation, } \\
f_{2}\left(D_{v d x}\left(T_{0}\right), T_{0}, t_{v d x}, \tau\right), \text { on exhalation, } T_{0} \leq \tau<T_{0}+t_{c}, \\
0, \text { on a respiratory break, }
\end{array}\right.
\end{aligned}
$$

where $D_{v d}\left(T_{0}\right)$ - the volume of the respiratory tract during inspiration; $D_{v d x}\left(T_{0}\right)$ - the volume of exhaled air from the respiratory tract into the environment;

$$
\int_{T_{0}}^{T_{0}+t_{v d}} f_{1}\left(D, T_{0}, t_{v d}, \tau\right) d \tau=D,
$$

$D_{v d}^{\grave{A}}\left(T_{0}\right)$ - inspiratory alveolar volume; $D_{v d x}^{A}\left(T_{0}\right)-$ alveolar volume on expiration; $\tau$ - time. Functions $f_{1}, f_{2}$ must be such that

$$
\int_{T_{0}+t_{v d}}^{T_{0}+t_{v d}+t_{v d x}} f_{2}\left(D, T_{0}, t_{v d x}, \tau\right) d \tau=D .
$$

Then, knowing that $V_{L}\left(T_{0}\right)=V_{L 0}\left(T_{0}\right)$, we can write the relation for $V_{L}$ :

$$
V_{L}(\tau)=\left\{\begin{array}{l}
V_{L 0}\left(T_{0}\right)+l \int_{T_{0}}^{\tau} f_{1}\left(D_{v d}^{\grave{A}}\left(T_{0}\right), T_{0}, t_{v d}, \xi\right) d \xi, \text { on inhalation, } \\
V_{L 0}\left(T_{0}\right)+l\left[D_{v d}^{\grave{A}}\left(T_{0}\right)-\int_{T_{0}+t_{v d}}^{\tau} f_{2}\left(D_{v d x}^{\grave{A}}\left(T_{0}\right), T_{0}, t_{v d x}, \xi\right) d \xi,\right. \text { on exhalation, } \\
V_{L 0}\left(T_{0}\right)+l\left[D_{v d}^{\grave{A}}\left(T_{0}\right)-D_{v d x}^{\grave{A}}\left(\grave{O}_{0}\right)\right]=V_{L 0}\left(T_{0}+t_{0}\right), \text { on a respiratory break. }
\end{array}\right.
$$


It should be noted that $T_{0} \leq \tau<T_{0}+t_{0}$ in (25). If we assume that the breathing mode of the lungs, in which relations (23) - (25) are used, is realized from the moment of time $\tau_{0}$, then the parameter $T_{0}$ from cycle to cycle will also discretely change, i.e. $T_{0}=\tau_{0}+(k-1) t_{c}, k=1,2, \ldots(k-$ breathing cycle number).

The parameters $D_{v d}, D_{v d x}, D_{v d}^{\grave{A}}, D_{v d x}^{\grave{A}}$ used in (24) - (25) are generally changing from cycle to cycle. Only in isolated cases $D_{v d}=D_{v d}^{\grave{A}}, D_{v d x}=D_{v d x}^{\grave{A}}$ or $D_{v d}=D_{v d x}=D_{v d}^{\grave{A}}=D_{v d x}^{\grave{A}}$. It is clear that these parameters, on the one hand, characterize the type of pulmonary respiration, and on the other, they have an active influence on the nature of gas exchange in the lungs. In order to take into account the resistance $R$ of the airways, the role of this parameter in the formation of ventilation $V_{D}$ and $V_{L}$ should be studied. If for $V_{D}, V_{L}$ the relations (23), (24) are applicable, then the resistance $R$ on $V_{D}, V_{L}$ will influence through $D_{v d x}, D_{v d}^{\grave{A}}, D_{v d x}^{\grave{A}}\left(D_{v d}\right.$ does not depend on $R$, since this respiratory volume is provided by the work of the respiratory muscles or an artificial lung ventilation apparatus).

Simulating the process of gas exchange in human lungs, the following relations were taken for $D_{v d x}, D_{v d}^{\grave{A}}, D_{v d x}^{\grave{A}}$ :

$$
\begin{aligned}
& D_{v d x}\left(T_{0}\right)=D_{v d}\left(1-\exp \left(-\frac{k_{1}}{\tau_{D}^{0}} \frac{R_{0}}{R} \frac{D_{v d}}{550}\left(T_{0}-\tau_{0}\right)\right)\right), \\
& D_{v d}^{\grave{A}}\left(T_{0}\right)=D_{v d}\left(1-\exp \left(-\frac{k_{2}}{\tau_{D}^{0}} \frac{R_{0}}{R} \frac{D_{v d}}{550}\left(T_{0}-\tau_{0}\right)\right)\right), \\
& D_{v d x}^{\grave{A}}\left(T_{0}\right)=D_{v d x}\left(T_{0}\right)\left(1-\exp \left(-\frac{k_{2}}{\tau_{D}^{0}} \frac{R_{0}}{R} \frac{D_{v d}}{550}\left(T_{0}-\tau_{0}\right)\right)\right),
\end{aligned}
$$

where $k_{1}, k_{2}-$ the coefficients; $\tau_{D}^{0}-$ temporary retention of the airways of the lungs with bronchial resistance $R_{0}$.

Thus, the mathematical model (1) - (20), as well as equations (21) - (28), represent the mathematical model of the process of gas exchange in the lungs, taking into account the role of elasticity $l$ and resistance $R$ of the lungs in the formation of the nature of the process of gas exchange in the lungs with one or another external respiration mode. Numerical experiments carried out with model (1) -
(28) confirm its adequacy to the process under study $[9,10,11,12,13]$.

Analysis of the simulate on results allows developing the specific recommendations for the use of artificial lung ventilation devices.

\section{CONCLUSIONS}

The developed imitational mathematical model of the gas exchange process in the lungs provided the opportunity to evaluate the role the elasticity and the resistance of the lung structures in the formation of the nature of the gas exchange process under various modes of external respiration. The deep insight in the mechanisms of the respiration provided the base to model the optimal lung ventilation under the conditions of changing environmental factors. The obtained results can serve as the basis for the construction of effective devices for artificial lung ventilation.

\section{REFERENCES}

1.Mead J., Mechanical properties of lungs, 1961 The American Physiological Society, 41(2), 1961, 281-330. https://doi.org/10.1152/physrev.1961.41.2.281

2. Hess D. R., R. M. Kacmarek, Essentials of Mechanical Ventilation, 2nd Edition, 2002

3. Papadakos P. J., B. Lachmann, Mechanical Ventilation: Clinical Applications and Pathophysiology, Saunders/Elsevier, Philadelphia 2008, 665 p. doi: 10.1213/01.ane.0000324503.60664.13

4. Bates J. Lung Mechanics: An Inverse Modeling Approach, Cambridge University Press, New York , 2009, 220 p

5. Onopchuk YU. N., Gomeostaz funkcional'noj sistemy dykhaniya kak rezul'tat vnutrisistemnogo i sistemno-sredovogo informacionnogo vzaimodejstviya, In: Bioehkomedicina. Edinoe informacionnoe prostranstvo (V. I. Gricenko, Eds.), Kiev, 2001, 59106, (in Russian)

6. Garashchenko F.G., N. Grabova, I. Lanovenko, $\mathrm{Ob}$ odnom mekhanizme avtoregulyacii processa dykhaniya $\mathrm{v}$ organizme i ego matematicheskoj modeli, Teoriya optimal'nykh reshenij, No 7, 2008, 139-145, (in Russian)

7. Kolchinskaya A., I. Man'kovskaya, A. Misyura, Dykhanie i kislorodnye rezhimy del'finov, Nauk. dumka, Kiev, 1980, 332 p., (in Russian).

8.Galchyna N., Iu. N. Onopchuk, V. I. Portnichenko, T. A. Siemchyk, Game Models for the Control of the Main Body Functional Systems and their Analysis I, Cybernetics and Systems Analysis, Vol. 50, Issue 1, Springer, 2014, 68-80. 
9. Galchyna N., Iu. Onopchuk, V. Portnichenko, T. Siemchyk, Game Models for the Control of the Main Body Functional Systems and their Analysis II, Cybernetics and Systems Analysis, Vol. 50, Issue 2, Springer,2014, 89-98. DOI: 10.1007/s10559-014-9611-y. 10. Aralova N.I., O.M. Klyuchko, V.I. Mashkin, I.V. Mashkina, T.A. Semchyk, Integrated mathematical model for imitation of the course of viral disease and correction of the induced hypoxic state, Biotechnologia Acta, 13, No 3, 2020, 30-44. DOI:10.15407/biotech13.03.030.

11. Aralova N.I., O.M. Klyuchko, V.I. Mashkin, I.V. Mashkina, T.A. Semchyk, Mathematical models of immune processes and their applications, Biotechnologia Acta, 14, No 5, 2020, 5-18. DOI:10.15407/biotech13.03.05.005.

12. Semchik T.A., Mekhani`zmi vzayemodi yi matematichnoyi modeli i`munnogo vi`dkliku z modelyami dikhannya, krovoobi `gu ta teploobmi`nu, Teori`ya optimal`nikh ri`shen`, 17, 2018, 92-98. (in Russian).

13. Gal'china N., G`. Korniush, T. Semchik, Matematichni` modeli` dlya kompleksnoyi oczi`nki funkczi`onal`nogo stanu organi`zmu lyudini $\mathrm{v}$ ekstremal'nikh umovakh, Teori ya optimal'nikh ri`shen`, 18, 2019, 13-18. (in Russian).

14. Akhlamov E'.A., I.I. Korniush, D.I. Marchenko, Yu.N. Onopchuk, Imitaczionnoe modelirovanie proczessa gazoobmena $\mathrm{v}$ legkikh $\mathrm{s}$ uchetom e`lastichnosti i soprotivleniya legochny`kh struktur, Kibernetika i vy`chisl. Tekhnika, 82, 1989, 60-63. (in Russian).

15. Pontryagin L.S., Selected scientific papers, 2, Nauka, Moscow, 1988, 576 p. (in Russian). Tetiana Semchyk, PhD, Researcher
Iryna Korniush, Junior Researcher

Glushkov Cybernetics Institute of the NAS of Ukraine,

Department of Optimization of controlled process, room 502

Address: 40, Glushkov Avenue, 03187, Kyiv, Ukraine

tel.: +380445265158

e-mails: tsemchik@googlemail.com

ii-kor@ukr.net

Vira Hovorukha, PhD, Senior Researcher

Deputy Head of the Department,

Zabolotny Institute of Microbiology and Virology of the NAS of Ukraine,

Department of Extremophilic Microorganism Biology, room 224

Address: 154, Zabolotny str., 03143, Kyiv, Ukraine

tel.: +380445263297

e-mail: vira-govorukha@ukr.net

\section{Prof. Oleksand Tashyrev}

Head of the Department,

Zabolotny Institute of Microbiology and Virology of the NAS of Ukraine,

Department of Extremophilic Microorganism Biology, room 224

Address: 154, Zabolotny str., 03143, Kyiv, Ukraine

tel.: +380445263297

e-mail: tach2007@ukr.net 